\title{
Mortality in the Elderly Due to Cerebrovascular Disease
}

\author{
Marco Antônio Mota Gomes ${ }^{1,2}$ and Annelise Machado Gomes de Paiva ${ }^{1,2}$ \\ Centro Universitário Cesmac, ${ }^{1}$ Maceió, AL - Brazil. \\ Centro de Pesquisas Clínicas Dr. Marco Mota (Centro Universitário Cesmac/Hospital do Coração de Alagoas - HCAL)², Maceió, AL - Brazil. \\ Editorial referring to the article: Elderly Mortality from Cerebrovascular Disease in Alagoas, 2000-2016: Spatial-Temporal Analysis
}

Cardiovascular Diseases (CVD) are the main cause of death, hospitalization and outpatient care worldwide, including in developing countries like Brazil. More than $75 \%$ of deaths from these causes occur in low- or middleincome countries, and about $80 \%$ of deaths are due to acute myocardial infarction (AMI) and stroke. ${ }^{1}$ Vilela, PB et al. ${ }^{2}$ observed that mortality from cerebrovascular disease in Brazil is influenced by socioeconomic factors.

Although the aging process is not necessarily related to diseases and disabilities, elderly people have a high prevalence of chronic non-communicable diseases (NCDs). In the period from 2010 to 2050, the number of strokes is expected to more than double, with most of the increase among the elderly ( $\geq 75$ years of age) and minority groups. ${ }^{3}$ Greater attention is needed to promote optimal cardiovascular health and healthy aging throughout life.

Stroke patients $>85$ years of age constitute $17 \%$ of all patients with this condition and, in this age group, this condition is more prevalent in women than in men. ${ }^{4}$ Risk factors for stroke may be different in older adults. A multiethnic population-based NOMAS cohort noted that the effect of the risk of physical inactivity was modified by age, and there was a significant risk only in stroke patients and age $>80$ years. $^{5}$

The article published by Silva Junior LCF et al., ${ }^{6}$ in this issue, describes the epidemiological profile and analyze the spatiotemporal dynamics of mortality from cerebrovascular diseases in elderly people from Alagoas in the period 20002016. Data were collected from the Mortality Information System. This study showed that deaths from CVD, in

\section{Keywords}

Cerebrovascular Disorders; Cardiovascular Diseases; Aged; Strove; Mortality; Epidemiology.
Alagoas, were the same between genders, and more evident in brown individuals, with low education, married and in the eastern region of the state. There was a downward trend in general mortality and mortality in males as of 2007. The need for public policies aimed at healthy aging in the state became evident.

Global rates of total CVD have significant implications for clinical practice and public health policy development. In 2021 the American Heart Association Council on Epidemiology and Prevention Statistics Committee and Stroke Statistics Subcommittee published the Heart Disease and Stroke Statistics - 2021 Update: a Report from the American Heart Association, 7 showing that age-standardized rates of DALYs (disability-adjusted life-year) and deaths due to cerebrovascular diseases were substantially higher in men than in women, but the prevalence was higher in women, suggesting the possibility of a higher risk of death and disability in men, but better survival in women. In 2019, total CVD DALYs were higher in men than in women before the age range of 80 to 84 . After that range, the pattern is reversed. The gender differences in DALYs are most striking between the ages of 30 and 60 years (older men) and age > 80 years (older women). The excess of deaths from CVD in women between the ages of 80 and 84 should focus attention on mortality from specific causes at older ages and have implications for secondary prevention strategies.

High mortality rates are currently being observed because of the pandemic of severe respiratory syndrome caused by the Sars-CoV-2 virus (COVID-19), and much of that additional disease burden may be cardiovascular disease due to the effects of viral infection, but also of the unintended consequence of socially distant behaviors, such as changes in healthcare provision. ${ }^{8}$ In the face of a viral pandemic, we must further emphasize global commitments to the health of the population by reducing suffering and death from cardiovascular disease. 


\section{References}

1. GBD 2016 Causes of Death Collaborators. Global, regional, and national age-sex specific mortality for 264 causes of death, 1980- 2016: a systematic analysis for the Global Burden of Disease Study . Lancet. 2017;390(10100):1151-210.

2. Villela PB, Klein $\mathrm{CH}$, de Oliveira GMM. Socioeconomic factors and mortality due to cerebrovascular and hypertensive disease in Brazil. Rev Port Cardiol. 2019 Mar;38(3):205-12.

3. Howard G, Goff DC. Population shifts and the future of stroke: forecasts of the future burden of stroke. Ann N Y Acad Sci. 2012; 1268:14-20.

4. Dehlendorff C, Andersen KK, Olsen TS. Sex disparities in stroke: women have more severe strokes but better survival than men. J Am Heart Assoc. 2015;4:e001967.

5. Willey JZ, Moon YP, Sacco RL, Greenlee H, Diaz KM, Wright CB, Elkind MS, Cheung YK. Physical inactivity is a strong risk factor for stroke in the oldest old: findings from a multi-ethnic population (the Northern Manhattan Study). Int J Stroke. 2017; 12(2):197-200.

6. Silva Junior LCF, Cunha EJOD, Souza CDF, Duarte AWF. Elderly Mortality from Cerebrovascular Disease in Alagoas, 2000-2016: Spatial -Temporal Analysis. Int J Cardiovasc Sci. 2021; 34(2):159-167.

7. Virani SS, Alonso A, Aparicio HJ, Benjamin EJ, Bittencourt MS, Callaway CW, et al.; on behalf of the American Heart Association Council on Epidemiology and Prevention Statistics Committee and Stroke Statistics Subcommittee. Heart disease and stroke statistics - 2021 update: a report from the American Heart Association. Circulation. 202127 Jan;143:e00-e00.

8. Wadhera RK, Shen C, Gondi S, Chen S, Kazi DS, Yeh RW. Cardiovascular Deaths During the COVID-19 Pandemic in the United States. J Am Coll Cardiol. 2021;77(2):159-69. 